Research Article

\title{
Effectiveness of Surgical Treatment in Carpal Tunnel Syndrome Mini-Incision Using MIS-CTS Kits: A Cadaveric Study
}

\author{
Wongthawat Liawrungrueang $(1)$ and Sunton Wongsiri $(D)$ \\ Department of Orthopaedic Surgery, Faculty of Medicine, Prince of Songkla University, Hat Yai, Thailand \\ Correspondence should be addressed to Wongthawat Liawrungrueang; mint11871@hotmail.com
}

Received 7 September 2019; Revised 21 December 2019; Accepted 8 January 2020; Published 14 February 2020

Academic Editor: Allen L. Carl

Copyright (C) 2020 Wongthawat Liawrungrueang and Sunton Wongsiri. This is an open access article distributed under the Creative Commons Attribution License, which permits unrestricted use, distribution, and reproduction in any medium, provided the original work is properly cited.

\begin{abstract}
Introduction. Carpal tunnel syndrome (CTS) is caused by the compression of the median nerves in the wrist. Patients have pain and numbness in the hands. According to the records of Songklanagarind Hospital from 2015 to 2018, of 800 patients, 196 or $24.5 \%$ were treated with surgery. The novel tool of minimally invasive surgery for carpal tunnel syndrome (MIS-CTS) was developed to improve effectiveness and safety. Purpose. This study was performed to the effectiveness of visualization during surgery and the complete release of the transverse carpal ligament (TCL) and also the safety of using the MIS-CTS kits. Methods. Twenty fresh cadaveric forearms had surgery. Surgical techniques were (1) incision 15-18 mm at palmar hand; (2) the scissors and the navigator were inserted to create working space underneath the palmar aponeurosis; (3) the visual enhancer was inserted. The visual enhancer improves the visual field by shielding the soft tissue around the operative field; (4) the TCL was cut at the distal TCL by surgery scalpel, and then a flexible freer was used to detach the fibrous tissue from the median nerve and the TCL; and (5) the TCL cutting blade was pushed straight to cut the TCL completely from distal to proximal. TCL length was observed until the complete release. The median nerve and the recurrent branch of the median nerve were observed. Results. All TCL were cut completely. All median nerves, recurrent branches of the median nerve, and superficial palmar arches could be observed during the operation, and none were injured. This technique showed effectiveness and safety for minimally invasive carpal tunnel surgery. Conclusions. The study found that the new device, MIS-CTS kits, along with this technique is effective for CTS release in terms of minimally invasive open carpal tunnel surgery.
\end{abstract}

\section{Introduction}

Carpal tunnel syndrome is common and has a high prevalence of $6-10 \%$ in the elderly population with an average age of 54 years. It is twice more common in women than in men [1-6]. The initial treatment of mild symptoms can be conservative. However, if symptoms are more frequent or persistent, including muscular weakness and decreased handgrip or drooping, surgical treatment may be required; $20 \%$ of people with the disease need surgery [7-11]. Standard open surgery is a basic procedure with a $3-5 \mathrm{~cm}$ long incision and produces successful outcomes of carpal tunnel release, but wound complications are more frequent than with minimally invasive carpal tunnel surgery. The most common wound complications are wound infection, inflammation, wound dehiscence, and painful scar $[9,12-15]$.
Minimally invasive carpal tunnel surgery techniques, such as endoscopic surgery, have less wound complications and patients can return to work faster than with the standard open technique; however, minimally invasive carpal tunnel surgery has other complications, including recurrent incidents and incomplete release [12, 16-19]. Minimally invasive carpal tunnel surgery was developed to improve visualization. It is a surgical tool that is important for complete release [20-23].

Nowadays, the medical costs are high, because of expensive surgical devices; the cost of endoscopic surgery carpal tunnel surgery is higher than that of standard open and other minimally invasive methods $[24,25]$. The complexity of tools and the surgical technique of endoscopic surgery require a longer learning curve for surgeons [26-28]. In order to eliminate the difficulties of use and 
cost, the first generation (PSU-CTR ${ }^{\circledR}$ ) and the second generation (named MiniSURE ${ }^{\circledR}$ ) of MIS-CTS kits were developed to help patients gain minimally invasive surgery outcomes (Figure 1). Now, surgery is easier because surgeons have greater visibility [22, 23, 29]. In previous studies of both generations of MIS-CTS kits, we found better outcomes with small wounds, less pain, and early return to work [29]. Nonetheless, we have improved some features in the next generation of kits, thus increasing effectiveness and safety. The new features include improved hand griping, antislipping with expandable visual enhancer, and insertion length of marker of TCL cutting blade and flexible freer. The purposes of this research are to study the effectiveness of visualization during surgery and the complete release of TCL and also the safety of using the MIS-CTS kits.

\section{Methods}

2.1. Study Subjects. This study was approved by the Institutional Review Board of Faculty of Medicine, Prince of Songkla University (IRB number EC 60-282-11-1). This study was performed on 20 forearms from 10 fresh cadavers obtained within 72 hours after death. The cadavers came from a donation center of faculty of science, Prince of Songkla University. The operation was performed by the same author. Procedures were performed in the supine position and described the landmark by Kaplan's cardinal line (Figure 2).

2.2. The Surgical Technique. The incision direction is the line between the middle finger and ring finger along the wrist crease. Incision of $15-18 \mathrm{~mm}$, starts away from the wrist crease about 2 to $2.5 \mathrm{~cm}$ distally. (Figure 3 )

The Palmaris longus tendon is retracted by Senn retractors, and then the TCL is observed at the base. Scissors are used to create working space underneath the PL tendon and palmar aponeurosis. Then, insert the navigator to increase the size of the space for visual enhancer insertion (Figure 4).

The visual enhancer is inserted in the space beneath the PL tendon and palmar aponeurosis. The transverse fiber of the TCL is observed from the bottom view. The visual enhancer improves the visual field by shielding the soft tissue around the operative field (Figure 5).

The TCL is cut by using a scalpel longitudinally at the top to create the long groove for the cutting guide and reducing the over prominence of TCL. The TCL is cut at the distal part for opening entry; then, a flexible freer is used to detach the fibrous tissue from the median nerve and the TCL (Figure 6).

The TCL cutting blade is pushed straight to cut the TCL from the distal to proximal along the groove until the antebrachial fascia that is 2 to 2.5 centimeters proximal to the wrist crease. (Figure 7). Finally, complete release can be directly checked by direct vision via the visual enhancer or through the use of a probe with the MIS-CTS kits, the TCL can be seen clearly through the small incision.

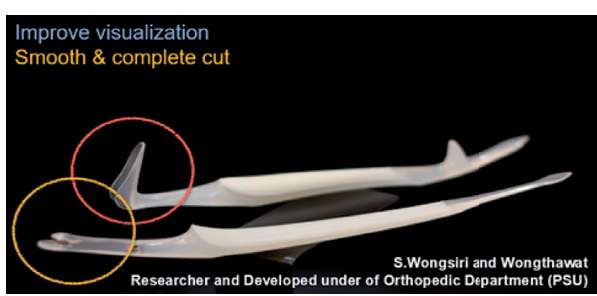

FIgURE 1: The minimally invasive surgery for carpal tunnel syndrome kits (MIS-CTS kits).

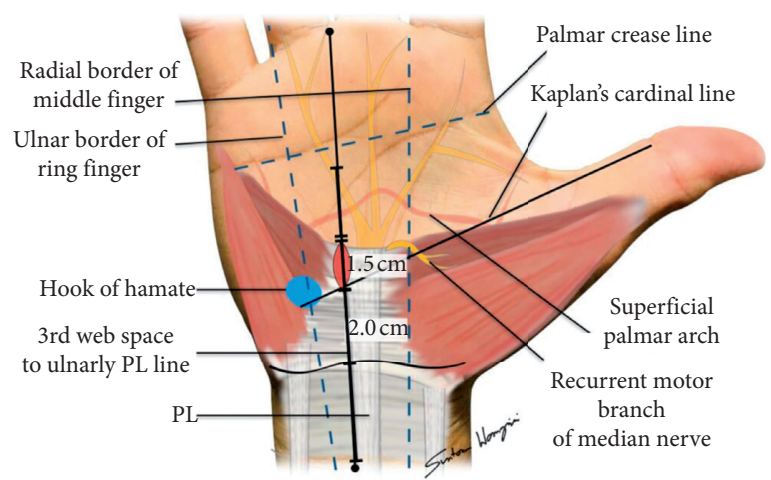

FIgUre 2: The landmark of anatomy of hand using Kaplan's cardinal line.

2.3. Statistical Analysis. The descriptive statistics was used in this study. Cadaveric data collected included sex, age, side of hand, transverse carpal ligament length, incision site for single portal, type of release (complete release/incomplete release), median nerve injury (yes/no), type of recurrent branch of median nerve, and recurrent branch of median nerve injury.

\section{Results}

This study was from 20 forearms from 10 fresh cadavers: age of 20 forearms ranged from $58-82$ years (average 73.8 years); fresh cadavers were 4 male and 6 female; and forearms were 10 right and 10 left. The incision for Mini-CTS was $15-18 \mathrm{~mm}$ (average $16.2 \mathrm{~mm}$ ). Transverse carpal ligaments were $26-36 \mathrm{~mm}$ (average $31 \mathrm{~mm}$ ). All Mini-CTS of carpal tunnel release were complete with no median nerve injury and no recurrent branch of median nerve injury (Table 1). The recurrent branches of the median nerve, 13 were type A (65\% in the extraligamentous type), 6 were type B (30\% in the subligamentous branching type), and 1 were type C (5\% in the transligamentous type) (Table 2). This technique was complete release TCL in all forearms.

\section{Discussion}

The new minimally invasive carpal tunnel release technique, the author's technique, using MIS-CTS kits, and enhanced visualization, offered a promising result in all 20 cadavers with complete release of TCL and no nerve or vascular injury. The modified minimally invasive technique using visual enhancer could improve the visualization for surgery. This technique can avoid incisions on the touching zone of 


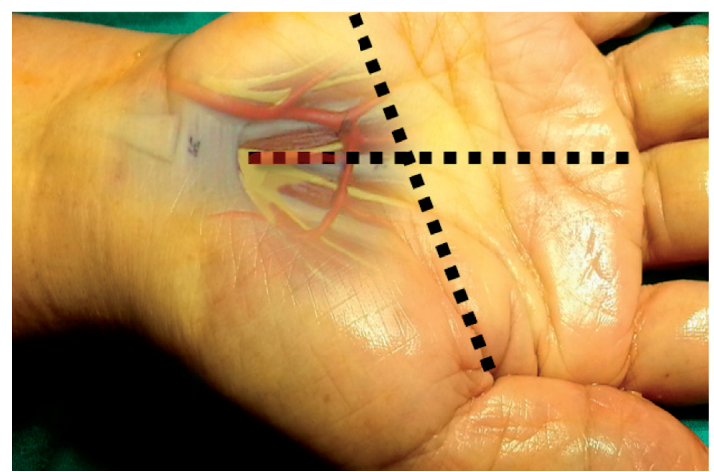

(a)

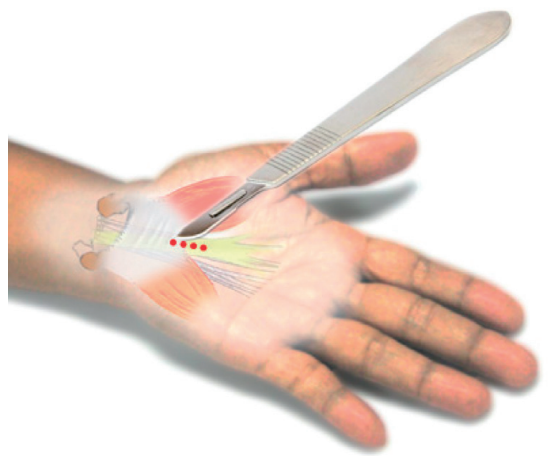

(b)

Figure 3: The first step for the author's surgical technique using MIS-CTS kits.

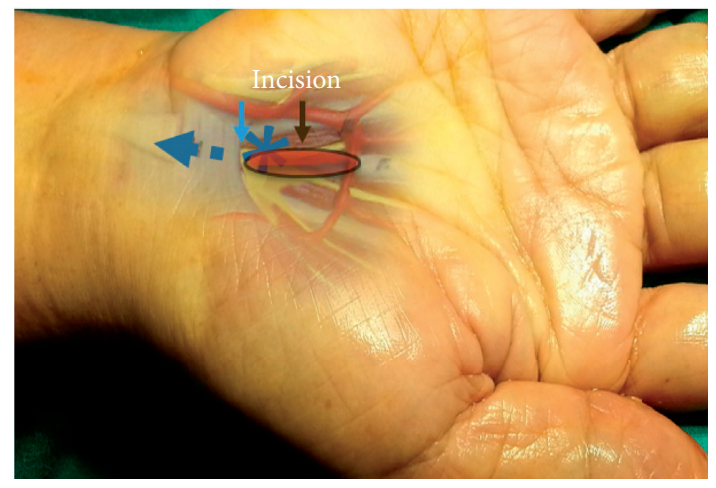

(a)

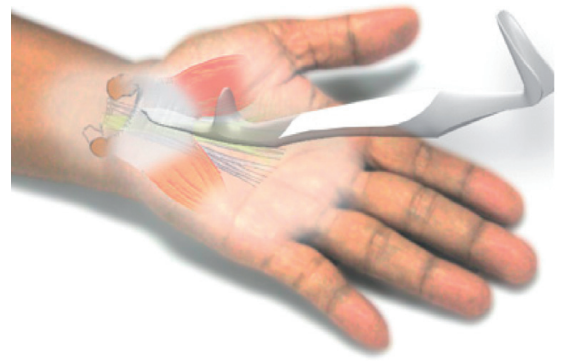

(b)

FIgUre 4: The second step for the author's surgical technique using MIS-CTS kits.

the hand, $2-2.5 \mathrm{~cm}$ from the wrist crease, which is a sensitive area for touching and bending. The touching zones are composed of the palmar cutaneous branches of the median nerve, which lie superficial to the transverse carpal ligament $[28,30-33]$. Palmar area operative scar may be related to the cause of chronic persistent pain, pillar pain, and slow return to work [14, 34-37]. Currently, the minimally invasive technique of carpal tunnel release is popular for patients due to its benefits and satisfaction.

In the previous study, the minimal invasive surgery of $1.5-1.8 \mathrm{~cm}$ skin incision was performed with the visual enhancer [22]. It showed significantly better maximal visual length compared with the Senn retractor $(47.7$ (8.1) $\mathrm{mm}$ vs. $39.2(6.5) \mathrm{mm}$ ). For careful attention of safety, the author's approach by the distal approach can gain benefit to observe directly in the superficial palmar vascular arch and recurrence branch of the median nerve. Also, when the TCL cutting blade is pushed straight from the distal to the proximal end of TCL, it can cut the TCL all at once.

In contrast, the endoscopic technique needs to cut TCL many times because the scalpel is designed to cut by layers from the bottom to the top. Sometimes, surgeons may have difficultly determining the other fascia from TCL when looking from the bottom of the endoscope view $[30,38]$. The brachial fascia look like TCL, and it also continues from TCL.
The author observed that the TCL cutting blade offered the promising result of complete detachment, and the smooth cutting edge did not fray any remnants. The author believes that the smooth cutting edge, without fraying remnants of TCL and both edges, can reduce the risk of recurrence. Usually, TCL requires many attempted cuts, such as using the scissors or the endoscope, which may risk fraying remnants with the rough edge of TCL. The author's technique using a scalpel is more effective. However, more research is required in order to determine the risks of recurrence, thus improving patient outcome. Because the lower tip is slim and short, pressure in the carpal tunnel is reduced. The concept of less pressure with a slim and short tip may be the right way to reduce nerve injury while inserting equipment; this aspect needs to be studied further. Most advice states not to insert an endoscope if there is severe compression or the tunnel is really tight. Because of a long incision of standard open CTS release, the complications and sequelae are mainly wound problems, scar pain, wound dehiscence, and slow return to work $[9,13,31,32]$. The minimally invasive technique was introduced for improving wound complication.

Minimally endoscopic carpal tunnel release is used to minimize wound problems. The endoscopic technique can approach from either portal 2 or portal 1 and makes an impressive minimal skin incision of $1.5 \mathrm{~cm}[16,18,33,39]$. 


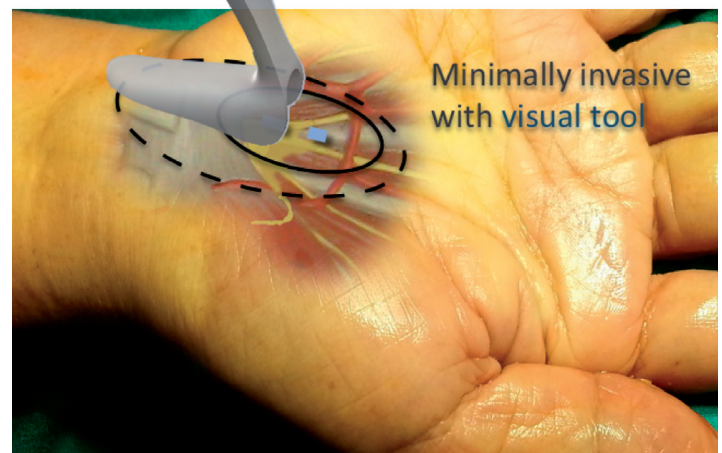

(a)

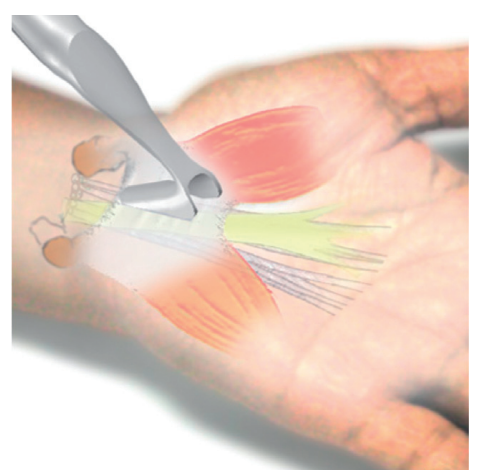

(b)

FIGURE 5: The third step for the author's surgical technique using MIS-CTS kits.

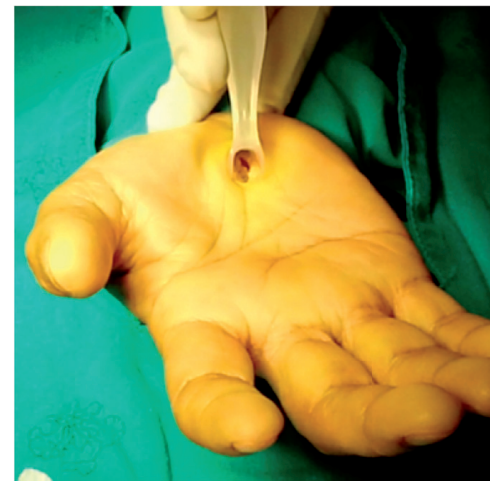

(a)

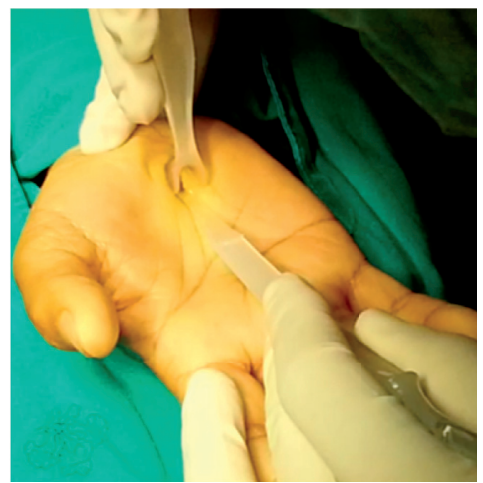

(b)

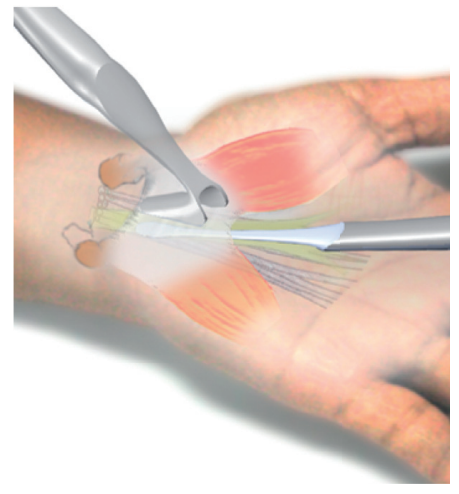

(c)

Figure 6: The fourth step for the author's surgical technique using MIS-CTS kits.

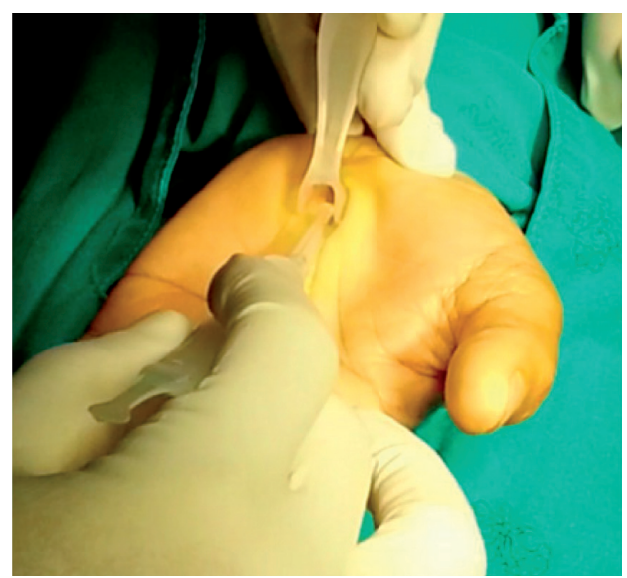

(a)

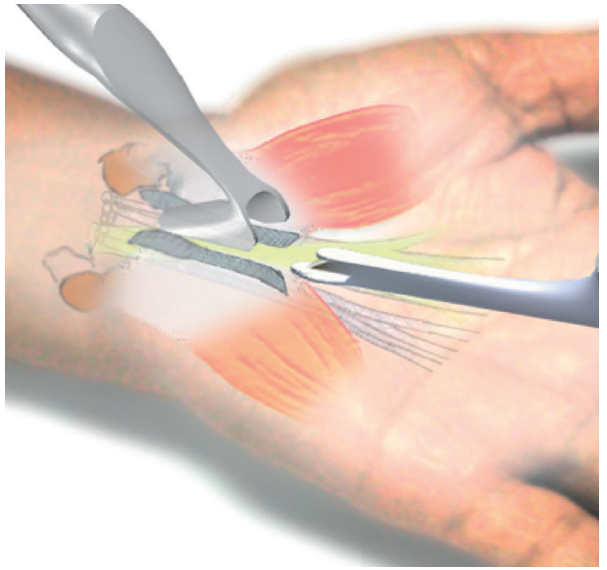

(b)

FIgURE 7: The fifth step for the author's surgical technique using MIS-CTS kits.

The meta-analysis of randomized controlled trials in the endoscopic versus open carpal tunnel release for idiopathic carpal tunnel syndrome significantly reduced postoperative hand pain, it increased the possibility of reversible postoperative nerve injury in patients with idiopathic CTS but statistical difference in the overall complication rate, subjective satisfaction, the time to return to work, postoperative grip and pinch strength, and operative time. However, the endoscope is an imaging and IT technology tool that needs special training with a longer learning curve [40]. Many studies found that transient nerve problems may occur during operations, especially inserting dilators or metallic equipment in the pressured carpal tunnel. The endoscope is not a proper device to use in severe compression. Once the 
TABLE 1: The results of carpal tunnel released by the MIS-CTS kits.

\begin{tabular}{|c|c|c|c|c|c|c|c|}
\hline Sex & $\begin{array}{c}\text { Cadaveric } \\
\text { forearm }(\mathrm{N})\end{array}$ & $\begin{array}{l}\text { Average age } \\
\text { (years) }\end{array}$ & $\begin{array}{c}\text { Average } \\
\text { incision }(\mathrm{mm})\end{array}$ & $\begin{array}{c}\text { Type of release } \\
\text { (complete/ } \\
\text { incomplete) }\end{array}$ & $\begin{array}{l}\text { Average TCL } \\
\text { length }(\mathrm{mm})\end{array}$ & $\begin{array}{l}\text { Median nerve } \\
\text { injury (\%) }\end{array}$ & $\begin{array}{l}\text { Recurrent branch of } \\
\text { median nerve injury } \\
(\%)\end{array}$ \\
\hline Male & $\begin{array}{c}\text { Left (4) } \\
\text { Right (4) }\end{array}$ & 67 & 16 & Complete $(100 \%)$ & 32.5 & 0 & 0 \\
\hline Female & $\begin{array}{c}\text { Left (6) } \\
\text { Right (6) }\end{array}$ & 78 & 16.63 & Complete $(100 \%)$ & 30 & 0 & 0 \\
\hline Total & 20 & 73 & 16.2 & Complete $(100 \%)$ & 31 & 0 & 0 \\
\hline
\end{tabular}

TABLE 2: Type of recurrent branches of the median nerve.

\begin{tabular}{lc}
\hline Type & $N(\%)$ \\
\hline Type A (extraligamentous type) & $13(65)$ \\
Type B (subligamentous branching type) & $6(30)$ \\
Type C (transligamentous type) & $1(5)$ \\
\hline
\end{tabular}

surgeon finds the obstacle during insertion of the tool, the surgeon must stop and convert to open carpal tunnel surgery because the median nerve may be damaged or torn.

The Indiana tome is a minimally invasive carpal tunnel surgery that uses local anesthesia and approaches the median nerve from the palm using a special scalpel to cut the TCL $[41,42]$. The Indiana tome simplified carpal tunnel surgery. It transformed carpal tunnel surgery to a faster, same day procedure. It seems the Indiana tome and other carpal tunnel tools, such as the Safeguard and Knight light, offer promising results, including complete TCL dividing, short incision, short operative time, and early return to work. However, the literature review highlights some nerve problems that can occur while using this equipment, even though some new developments have reduced the size of equipment $[41,43,44]$. We have developed both a new equipment and a new technique to avoid using the cannula and dilator, which may increase pressure on the carpal tunnel. We believe that minimal insertion in high-pressured carpal tunnel will reduce the risk of transient neuropathy; however, further clinical studies are required. The AAOS published recommendations for CTS: visualization and completely dividing TCL are the major roles of CTS [45]. Authors also believe the same important points. Currently, we are developing a visualization tube for improving visualization and a specific TCL knife for complete release. It is possible to improve the technique and the tool. This technique and the tool can perform the minimally invasive technique $[22,23]$. It offers a simplified technique with good outcomes of improved visualization and complete release. For the benefit of patients, it should reduce operative pain, touching scar pain, wound complication, and transient neuropathy and offer an early return to work. For the benefit of surgeons, the distal incision made using the special visual enhancer should improve visualization and improve safety while preventing injury of the median nerve, the ulnarmedian nerve palmar communicating branch, and the superficial palmar arch. For the benefit of the healthcare system: it may reduce the currently critically high costs of surgery. In 2002, Martin reported that CTS cost 4 billion dollars annually. In 2003, the increasing cost of healthcare is
$12 \%$. The healthcare system could save from lower costs for equipment, minimal equipment usage, shortened operative service costs, no anesthetic team, one surgeon, and one nurse.

The author's technique and the novel tool can improve effectiveness from the original standard of open release of CTS with both practical benefits (simple to use, enhanced visualization, complete cut) and productivity benefits (MIS, save time, save cost, and quick return to work). In the current era of high-cost healthcare, the author hopes that author's method will provide affordability for more patients to receive quality service. If any surgical technique and equipment is developed with the same concept of value, the healthcare costs will be reduced for patients, including health insurance and government support. This is the only cadaveric study which proves the concept. However, the author believes that a clinical study is important for the next stage.

\section{Conclusion}

This study found that the author's device (MIS-CTS kits) with the author's technique was effective and safe for TCL completely release in terms of minimally invasive open carpal tunnel surgery.
Abbreviations
TCL: $\quad$ Transverse carpal ligament
CTS: Carpal tunnel syndrome
OCTR: Open carpal tunnel release
ECTR: Endoscopic carpal tunnel release
MIS-CTS Minimally invasive surgery for carpal tunnel
kits: $\quad$ syndrome kits.

\section{Data Availability}

No external data are applicable to this manuscript.

\section{Conflicts of Interest}

The authors have no conflicts of interest with regard to this work.

\section{Authors' Contributions}

Wongthawat Liawrungrueang carried out the experimental study, performed the statistical analysis, and drafted the manuscript. Wongthawat Liawrungrueang and Sunton 
Wongsiri participated in surgery by the author's technique with MIS-CTS kits. All authors read and approved the final manuscript.

\section{Acknowledgments}

This research article was presented by W. Liawrungrueang at the Conference: JOA2019, the $92^{\text {nd }}$ Annual Meeting of the Japanese Orthopaedic Association "The Power of Orthopeadics as the Power of Japan" JOA Congress 2019 Travel Award). The authors thank the Department of Orthopedic Surgery, Faculty of Medicine, Prince of Songkla University, for their support. This study was supported by the Faculty of Medicine, Prince of Songkla University research fund.

\section{References}

[1] I. Atroshi, C. Gummesson, R. Johnsson, and A. Sprinchorn, "Symptoms, disability, and quality of life in patients with carpal tunnel syndrome," The Journal of Hand Surgery (American Volume), vol. 24, no. 2, pp. 398-404, 1999.

[2] A. Zyluk and P. Puchalski, "Natural history of carpal tunnel syndrome-a review," Chirurgia Narzadów Ruchu i Ortopedia Polska, vol. 75, no. 4, pp. 261-266, 2010.

[3] I. Atroshi, C. Gummesson, R. Johnsson, E. Ornstein, J. Ranstam, and I. Rosén, "Prevalence of carpal tunnel syndrome in a general population," The Journal of the American Medical Association, vol. 282, no. 2, pp. 153-158, 1999.

[4] L. E. Wessel, D. T. Fufa, M. I. Boyer, and R. P. Calfee, "Epidemiology of carpal tunnel syndrome in patients with single versus multiple trigger digits," The Journal of Hand Surgery, vol. 38, no. 1, pp. 49-55, 2013.

[5] L. Padua, D. Coraci, C. Erra et al., "Carpal tunnel syndrome: clinical features, diagnosis, and management," The Lancet Neurology, vol. 15, no. 12, pp. 1273-1284, 2016.

[6] M. Osterman, A. M. Ilyas, and J. L. Matzon, "Carpal tunnel syndrome in pregnancy," Orthopedic Clinics of North America, vol. 43, no. 4, pp. 515-520, 2012.

[7] G. A. Demopulos and J. R. Urbaniak, "Carpal tunnel release: comparing the options," Journal of Musculoskeletal Medicine, vol. 13, pp. 51-58, 1996.

[8] T. A. Tran and R. M. Szabo, "Surgical release of the carpal tunnel," in Operative Dictations in Plastic and Reconstructive Surgery, pp. 489-491, Springer, Berlin, Germany, 2017.

[9] A. W. Siegmeth and J. A. Hopkinson-Woolley, "Standard open decompression in carpal tunnel syndrome compared with a modified open technique preserving the superficial skin nerves: a prospective randomized study," The Journal of Hand Surgery, vol. 31, no. 9, pp. 1483-1489, 2006.

[10] J. H. J. English and D. P. Gwynne-Jones, "Incidence of carpal tunnel syndrome requiring surgical decompression: a 10.5year review of 2,309 patients," The Journal of Hand Surgery, vol. 40, no. 12, pp. 2427-2434, 2015.

[11] M. Fajardo, S. H. Kim, and R. M. Szabo, "Incidence of carpal tunnel release: trends and implications within the United States ambulatory care setting," The Journal of Hand Surgery, vol. 37, no. 8, pp. 1599-1605, 2012.

[12] A. A. M. Gerritsen, B. M. J. Uitdehaag, D. Van Geldere, R. J. P. M. Scholten, H. C. W. De Vet, and L. M. Bouter, "Systematic review of randomized clinical trials of surgical treatment for carpal tunnel syndrome," British Journal of Surgery, vol. 88, no. 10, pp. 1285-1295, 2001.
[13] M. Tarallo, P. Fino, V. Sorvillo, P. Parisi, and N. Scuderi, "Comparative analysis between minimal access versus traditional accesses in carpal tunnel syndrome: a perspective randomised study," Journal of Plastic, Reconstructive \& Aesthetic Surgery, vol. 67, no. 2, pp. 237-243, 2014.

[14] E. M. Mack, N. J. Callinan, M. Reams, D. C. Bohn, and T. L. Chmielewski, "Patient-reported outcomes after open carpal tunnel release using a standard protocol with 1 hand therapy visit," Journal of Hand Therapy, vol. 30, no. 1, pp. 58-64, 2017.

[15] S. Aroori and R. A. J. Spence, "Carpal tunnel syndrome," The Ulster Medical Journal, vol. 77, no. 1, pp. 6-17, 2008.

[16] I. Okutsu, S. Ninomiya, Y. Takatori, and Y. Ugawa, "Endoscopic management of carpal tunnel syndrome," Arthroscopy: The Journal of Arthroscopic \& Related Surgery, vol. 5, no. 1, pp. 11-18, 1989.

[17] J. M. Agee, H. R. McCarroll, and E. R. North, "Endoscopic carpal tunnel release using the single proximal incision technique," Hand Clinics, vol. 10, no. 4, pp. 647-659, 1994.

[18] T. B. Hansen and H. G. Majeed, "Endoscopic carpal tunnel release," Hand Clinics, vol. 30, no. 1, pp. 47-53, 2014.

[19] J. C. Y. Chow and M. E. Hantes, "Endoscopic carpal tunnel release: thirteen years' experience with the chow technique," The Journal of Hand Surgery, vol. 27, no. 6, pp. 1011-1018, 2002.

[20] Y. Iwase, T. Ikai, A. Hara, K. Mori, and K. Kusonose, "Carpal tunnel release through a small incision using a special knife guide," Techniques in Hand and Upper Extremity Surgery, vol. 6, no. 4, pp. 193-195, 2002.

[21] M. K. Abouzahr, M. C. Patsis, and D. T. W. Chiu, "Carpal tunnel release using limited direct vision," Plastic and Reconstructive Surgery, vol. 95, no. 3, pp. 534-538, 1995.

[22] S. Wongsiri, P. Suwanno, B. Tangtrakulwanich, V. Yuenyongviwat, and E. Wongsiri, "A new tool for mini-open carpal tunnel release-the PSU retractor," BMC Musculoskeletal Disorders, vol. 9, no. 1, p. 126, 2008.

[23] S. Wongsiri, "The new wave of carpal tunnel syndrome (CTS) surgery," The Bangkok Medical Journal, vol. 6, no. 1, pp. 80-85, 2013.

[24] D. H. Palmer and L. P. Hanrahan, "Social and economic costs of carpal tunnel surgery," Instructional Course Lectures, vol. 44, no. 44, pp. 167-172, 1995.

[25] A. Thoma, V. H. Wong, S. Sprague, and E. Duku, "A costutility analysis of open and endoscopic carpal tunnel release," Canadian Journal of Plastic Surgery, vol. 14, no. 1, pp. 15-20, 2006.

[26] M. Chammas, "Carpal tunnel syndrome," Chirurgie de la Main, vol. 33, no. 2, pp. 75-94, 2014.

[27] J. D. Beck, J. H. Deegan, D. Rhoades, and J. C. Klena, "Results of endoscopic carpal tunnel release relative to surgeon experience with the agee technique," The Journal of Hand Surgery, vol. 36, no. 1, pp. 61-64, 2011.

[28] J. M. R. Serra, J. R. Benito, and J. Monner, "Carpal tunnel release with short incision," Plastic and Reconstructive Surgery, vol. 99, no. 1, pp. 129-135, 1997.

[29] S. Wongsiri, "Keyhole surgery of CTS using novel tool MiniSure," BMC Proceedings, vol. 9, no. S3, p. A79, 2015.

[30] S. Uchiyama, K. Nakamura, T. Itsubo et al., "Technical difficulties and their prediction in 2-portal endoscopic carpal tunnel release for idiopathic carpal tunnel syndrome," $A r$ throscopy: The Journal of Arthroscopic \& Related Surgery, vol. 29, no. 5, pp. 860-869, 2013. 
[31] P.-T. Kim, H.-J. Lee, T.-G. Kim, and I.-H. Jeon, "Current approaches for carpal tunnel syndrome," Clinics in Orthopedic Surgery, vol. 6, no. 3, pp. 253-257, 2014.

[32] S. Suppaphol, P. Worathanarat, V. Kawinwongkovit, and P. Pittayawutwinit, "The comparison between limited open carpal tunnel release using direct vision and tunneling technique and standard open carpal tunnel release: a randomized controlled trial study," Journal of the Medical Association of Thailand, vol. 95, pp. 532-536, 2012.

[33] M. A. Mirza, E. T. King, and S. Tanveer, "Palmar uniportal extrabursal endoscopic carpal tunnel release," Arthroscopy: The Journal of Arthroscopic \& Related Surgery, vol. 11, no. 1, pp. 82-90, 1995.

[34] P. S.-H. Yung, L.-K. Hung, C. W.-C. Tong, and P.-C. Ho, "Carpal tunnel release with a limited palmar incision: clinical results and pillar pain at 18 months follow-up," Hand Surgery, vol. 10, no. 1, pp. 29-35, 2005.

[35] S. Avci and U. Sayli, "Carpal tunnel release using a short palmar incision and a new knife," Journal of Hand Surgery, vol. 25 , no. 4, pp. 357-360, 2000.

[36] P. Cellocco, C. Rossi, S. El Boustany, G. L. Di Tanna, and G. Costanzo, "Minimally invasive carpal tunnel release," Orthopedic Clinics of North America, vol. 40, no. 4, pp. 441448, 2009.

[37] K. S. Ludlow, J. L. Merla, J. A. Cox, and L. N. Hurst, "Pillar pain as a postoperative complication of carpal tunnel release," Journal of Hand Therapy, vol. 10, no. 4, pp. 277-282, 1997.

[38] T. Y. Law, S. Rosas, Z. S. Hubbard, L. O. Chieng, and H. W. Chim, "Trends in open and endoscopic carpal tunnel release utilization in the Medicare patient population," Journal of Surgical Research, vol. 214, pp. 9-13, 2017.

[39] L. S. Benson, A. A. Bare, D. J. Nagle, V. S. Harder, C. S. Williams, and J. L. Visotsky, "Complications of endoscopic and open carpal tunnel release," Arthroscopy, vol. 22, no. 9, pp. 924-924.e2, 2006.

[40] D. Zuo, Z. Zhou, H. Wang et al., "Endoscopic versus open carpal tunnel release for idiopathic carpal tunnel syndrome: a meta-analysis of randomized controlled trials," Journal of Orthopaedic Surgery and Research, vol. 10, no. 1, p. 12, 2015.

[41] W. P. A. Lee, B. M. Schipper, and R. J. Goitz, "13-Year experience of carpal tunnel release using the Indiana tome technique," The Journal of Hand Surgery, vol. 33, no. 7, pp. 1052-1056, 2008.

[42] C. B. Chapman, S. Ristic, and M. P. Rosenwasser, "Complete median nerve transection as a complication of carpal tunnel release with a carpal tunnel tome," American Journal of Orthopedics, vol. 30, no. 8, pp. 652-653, 2001.

[43] T. B. Hughes and M. Baratz, "Limited open carpal tunnel syndrome using the safeguard system," Techniques in Orthopaedics, vol. 21, no. 1, pp. 12-18, 2006.

[44] T. L. Atik, B. Smith, and M. E. Baratz, "Risk of neurovascular injury with limited-open carpal tunnel release: defining the "safe-zone"," Journal of Hand Surgery, vol. 26, no. 5, pp. 484-487, 2001.

[45] M. W. Keith, V. Masear, P. C. Amadio et al., "Treatment of carpal tunnel syndrome," Journal of the American Academy of Orthopaedic Surgeons, vol. 17, no. 6, pp. 397-405, 2008. 